\title{
PENINGKATAN KEMAMPUAN PERAWAT DALAM TERAPI AKTIFITAS KELOMPOK STIMULASI PERSEPSI HALUSINASI
}

\author{
(Nursing Capability Improvement on Hallucinations Perceptual \\ Stimulation Activity Therapy)
}

\author{
Dya Sustrami ${ }^{1)}$, Sukma Ayu Candra Kirana ${ }^{2)}$ \\ ${ }^{1}$ STIKes Hang Tuah Surabaya \\ email : dyastaufan@gmail.com \\ ${ }^{2}$ STIKes Hang Tuah Surabaya \\ email : sukmaayucandrakirana@stikeshangtuah-sby.ac.id
}

\begin{abstract}
ABSTRAK
Peran perawat dalam keperawatan jiwa adalah salah satu hal penting dalam meningkatkan status kesehatan pasien dengan gangguan mental. Salah satu peran perawat dalam asuhan keperawatan jiwa adalah pelaksanaan asuhan keperawatan bagi individu, kelompok dan keluarga. Terapi aktivitas kelompok adalah salah satu bentuk psikoterapi yang dapat diberikan untuk meningkatkan kemampuan klien dan mengurangi tanda-tanda dan gejala pasien, yang telah terbukti dalam penelitian dosen STIKES Hang Tuah Surabaya. Metode yang digunakan adalah pendidikan kesehatan yang diberikan melalui pengabdian masyarakat. Pengabdian masyarakat tersebut dilakukan pada 31 Mei - 4 Juni 2018 pada 23 perawat di Rumkital Dr Ramelan Surabaya. Ada empat kegiatan program yang dilaksanakan, yaitu edukasi tentang TAK Sensori Persepsi Halusinasi, pre test dan post test TAK, dilanjutkan dengan pendampingan dan monitoring secara kontinu. Hasil yang didapatkan adalah terdapat peningkatan kemampuan perawat sebelum dan sesudah pelatihan TAK. Pendampingan dan monitoring terus menerus diperlukan agar TAK menjadi kegiatan yang dijadwalkan.
\end{abstract}

Kata kunci: halusinasi, kelompok kegiatan, pengetahuan perawat

\begin{abstract}
The role of nurses in psychiatric nursing is one of the important things in improving the health status of patients with mental disorders. One role of nurses in nursing care is the implementation of nursing care for individuals, groups and families. Terapi Aktifitas Kelompok is one of the psychotherapy that can be given to improve client ability and reduce the signs and symptoms of patients, which has been proven in the research lecturer of STIKES Hang Tuah Surabaya. The method used is health education provided through community service. Community service was conducted on May 31 - June 4, 2018 on 23 nurses in Rumkital Dr Ramelan Surabaya. There are four program activities conducted, education about TAK Sensori Perception Hallucinations, pre test and post test of TAK, followed by continuous guidance and monitoring. The result is that there is an increase of nurse skills before and after TAK training. Continuous mentoring and monitoring is needed to avoid TAK being scheduled activity.
\end{abstract}

Keywords : hallucinations, activity group, nurse knowledge

PENDAHULUAN
Salah satu upaya untuk
meningkatkan mutu pelayanan
keperawatan jiwa adalah dengan
melakukan Terapi Aktivitas Kelompok
(TAK). TAK merupakan salah satu
terapi modalitas yang diberikan untuk
klien gangguan jiwa. TAK sangat efektif
mengubah perilaku karena di dalam
kelompok terjadi interaksi satu dengan

yang lain, saling pengaruh mempengaruhi, saling tergantung, dan terjalin satu persetujuan kelompok yang diakui bersama dan akan terbentuk suatu sistem yang khas yang selain terjadi interaksi, juga interelasi, interdependensi, dan saling membagi tujuan dan norma yang sama (Stuart \& Laraia 2001). Berdasarkan dari hasil pengamatan peneliti selama dinas di 
Ruangan Jiwa Rumkital Dr. Ramelan Surabaya, pada kenyataannya TAK masih jarang dilaksanakan. Hal ini terjadi karena tidak semua perawat mempunyai pengetahuan yang baik tentang TAK.

Jumlah total perawat di Ruang Jiwa Rumkital Dr. Ramelan Surabaya adalah 30 orang, yang terdiri dari 15 orang lulusan D III Akper, 13 orang lulusan SPK dan 2 orang lulusan SPR. Berdasarkan dari studi pendahuluan pengetahuan perawat tentang Terapi Aktivitas Kelompok dari 10 orang perawat yang diambil secara acak didapatkan hasil 3 perawat mempunyai pengetahuan baik, 4 perawat mempunyai pengetahuan cukup, dan 3 perawat mempunyai pengetahuan kurang.

Kurangnya pengetahuan perawat tentang TAK dapat dipengaruhi antara lain pendidikan, pengalaman dan informasi. Dengan kurangnya pengetahuan perawat tentang TAK maka akan berdampak pada tidak terlaksananya TAK itu sendiri. Karena perawat tidak bisa menjadi terapis. Kalaupun TAK tetap dilaksanakan maka hasilnya tidak seoptimal mungkin atau tidak sesuai dengan tujuan sehingga perawat tidak mampu meningkatkan mutu pelayanan keparawatan jiwa yang diberikan oleh Rumah Sakit. Tidak adanya intervensi TAK yang tepat dalam merawat klien gangguan jiwa dapat menimbulkan masalah-masalah lain yang lebih serius misal pada klien dengan menarik diri merasa tidak diperhatikan dan akhirnya mengalami depresi berat akan mengakibatkan klien murung, tidak bersemangat, merasa tidak berharga. Pada klien dengan halusinasi klien tidak bisa mengontrol halusinasi sehingga membahayakan diri dan orang lain. Pemberian terapi baik psikofarmaka maupun keperawatan yang tepat dan akurat saja tidaklah cukup pada klien gangguan jiwa, tetapi harus disusul atau bahkan paralel dengan terapi modalitas salah satunya dengan TAK yang secara kontinue dan teratur sampai berfungsinya kembali perilaku normatif yang stabil atau dalam istilah keperawatan perilakunya adaptif (Sarka Ade Susana, 2007 : 9).

Dari pengalaman dan penelitian bahwa perilaku yang didasari oleh pengetahuan akan lebih baik dan lebih langgeng dari pada perilaku yang tidak didasari dengan pengetahuan (Notoadmodjo, 2007:140). Diharapkan dengan tingkat pengetahuan perawat yang baik tentang TAK maka dapat meningkatkan mutu pelayanan keperawatan jiwa yang diberikan oleh rumah sakit. Berbagai cara untuk meningkatkan pengetahuan adalah dengan mengikuti pendidikan, dan dengan adanya seseorang yang melaksanakan pendidikan diharapkan seseorang tersebut makin luas pula pengetahuannya seperti yang ditetapkan oleh Koentjoroningrat yang dikutip oleh Nursalam atau Siti Pariani (2001:133) bahwa pendidikan diperlukan untuk mendapatkan informasi. Disamping itu untuk memperluas pengetahuan bisa melalui media informasi yang telah diperoleh dari berbagai sumber literatur yang lebih jelas dan lugas, media masa dan mengikuti berbagai seminar ataupun pelatihan-pelatihan sehingga dengan pengetahuan yang luas dapat mempermudah perawat dalam melaksanakan tindakan keperawatan yang berkualitas tinggi. Menurut Stuart dan Sunden, 1998:138 tentang standar kinerja profesional keperawatan jiwa yaitu standar III (pendidikan) untuk meningkatkan keahlian keperawatan dan pengembangan profesi perawat kesehatan jiwa-psikiatri mengikuti dan mempertahankan pengetahuan dalam praktik keperawatan, pendidikan formal, pendidikan berkelanjutan, sertifikasi, dan belajar dari pengalaman. Menurut peneliti solusi untuk ruang jiwa Rumkital Dr. Ramelan agar semua perawat mempunyai pengetahuan yang baik tentang TAK, maka perawat harus meningkatkan pendidikan, mencari informasi misalnya diadakan pelatihan. Sebaiknya TAK juga dilaksanakan sesering mungkin oleh perawat yang mempunyai pengetahuan baik dan 
pelaksanaannya terkoordinir oleh kepala ruangan, sehingga perawat yang mempunyai pengetahuan yang cukup dan kurang tentang TAK dapat belajar dari perawat tersebut.

Oleh sebab itu STIKES Hang Tuah Surabaya mengadakan pengabdian masyarakat berupa pelatihan Terapi Aktifitas Kelompok Stimulasi Persepsi : Halusinasi dengan harapan perawat Ruangan Jiwa Rumkital dr Ramelan Surabaya mengalami peningkatan pengetahuan dan kemampuan.

\section{KAJIAN LITERATUR}

Pengetahuan (knowledge) merupakan hasil dari tahu, dan ini terjadi setelah orang melakukan penginderaan terhadap suatu objek tertentu. Penginderaan terjadi melalui panca indra manusia, yakni indra penglihatan, pendengaran, penciuman, rasa dan raba. Sebagian besar pengetahuan manusia diperoleh melalui mata dan telinga (Soekidjo Notoatmodjo, 2003 : 120). Pengetahuan adalah kesan di dalam pikiran manusia sebagai hasil penggunaan panca inderanya, yang berbeda sekali dengan kepercayaan, takhayul dan penerangan-penerangan yang keliru (Soerjono Soekanto, 2002 : $6)$.

Penelitian Rogers (1974) yang dikutip oleh Soekidjo Notoatmodjo (2007 : 140) mengungkapkan bahwa sebelum orang mengadopsi perilaku baru, di dalam diri orang tersebut terjadi proses yang berurutan, yakni: Awareness, Interest, Evaluation, Trial, Adaptation. Awareness (kesadaran), yang dimaksud adalah kondisi dimana orang tersebut menyadari dalam arti mengetahui stimulus (objek) terlebih dahulu. Interest, yakni orang mulai tertarik kepada stimulus dan akhirnya mulai terjadi Evaluation (menimbangnimbang baik dan tidaknya stimulus tersebut bagi dirinya). Hal ini berarti sikap responden sudah lebih baik lagi. Proses selanjutnya adalah Trial, dimana orang telah mulai mencoba perilaku baru. Apabila orang tersebut tertarik maka langkah beriktnya yaitu Adoption, dimana subjek telah berperilaku baru sesuai dengan pengetahuan, kesadaran, dan sikapnya terhadap stimulus.

Faktor faktor yang mempengaruhi pengetahuan terdiri dari ; pendidikan, pengalaman, usia, budaya, sosial ekonomi dan terjangkaunya informasi akan hal yang diinginkan dalam hal ini adalah Terapi Aktifitas Kelompok. Kelompok adalah kumpulan individu yang memiliki hubungan satu dengan yang lain, saling bergantung dan mempunyai norma yang sama (Stuart dan Laraia, 1998). Terapi Aktivitas Kelompok adalah suatu upaya untuk memfasilitasi psiko terapi terhadap sejumlah klien pada waktu yang sama untuk memantau dan meningkatkan hubungan interpersonal antar anggota. Sedangkan Terapi aktivitas Kelompok menurut Wilson dan Kneisl (1992) yang dikutip oleh Budi Anna Keliat dan Akemat (2005:13) merupakan manual rekreasi, dan tehnik kreatif untuk memfasilitasi pengalaman seseorang dalam meningkatkan respon sosial dan harga diri. Aktivitas yang digunakan sebagai terapi yaitu membaca puisi, seni musik dan menari.

Terapi aktifitas memiliki beberapa macam. Namun yang akan dibahas dalam hasil pengabdian masyarakat kali ini adalah TAK Stimulasi Persepsi : Halusinasi. TAK Stimulasi Persepsi adalah terapi yang menggunakan aktivitas mempersepsikan berbagai stimulus yang terkait dengan pengalaman atau kehidupan untuk didiskusikan dalam kelompok. Hasil diskusi kelompok dapat berupa kesepakatan persepsi atau alternatif penyelesaian masalah. Tujuan dari pelaksanaan TAK tersebut adalah Klien mempunyai kemampuan menyelesaikan masalah halusinasinya dengan tepat.

\section{METODE KEGIATAN}

Waktu, Lokasi dan Partisipan

Kegiatan pengabdian masyarakat STIKES Hang Tuah Surabaya ini dilakukan di Ruang Jiwa Rumkital dr 
Ramelan Surabaya. Kegiatan ini melibatkan 23 perawat sebagai responden. Pelatihan TAK ini dilakukan selama 5 hari dimulai dari pre test, pemberian pelatihan tentang TAK Stimulasi persepsi dan diakhiri dengan post test. Pelaksanaan kegiatan dilakukan pada bulan Mei 2018.

\section{Alat dan Bahan}

Peralatan dan bahan yang digunakan dalam kegiatan pelatihan perawat berupa modul, proposal TAK Stimulasi Persepsi Halusinasi, Kuesioner pengetahuan TAK dan Lembar Observasi kemampuan perawat tentang TAK, serta materi penyuluhan yang disiapkan dalam bentuk power point. Kemudian untuk pelaksanan TAK yang dibutuhkan adalah bola, tape untuk musik, label nama pasien dan perawat.

\section{Metode Pelaksanaan Kegiatan}

Metode pelaksanaan yang digunakan pada kegiatan pengabdian masyarakat ini terdiri dari : pengukuran tingkatan pengetahuan dan kemampuan perawat tentang TAK sebelum pelaksanaan pelatihan TAK, pelaksanaan penyuluhan TAK kemudian pengukuran tingkat pengetahuan dan kemampuan perawat tentang TAK sesudah pelaksanaan pelatihan TAK. Metode yang digunakan menggunakan metode Focus Group Discussion (FGD).

\section{Metode Pengumpulan Data}

Kegiatan pengabdian masyarakat ini menggunakan data primer dan sekunder. Pengumpulan data primer melalui dua cara, yaitu wawancara dan observasi dengan data demografi maupun kuesioner pengetahuan perawat tentang TAK. Data primer diperoleh dari data pengetahuan dan kemampuan perawat terhadap TAK sebelum dan sesudah mendapatkan pelatihan TAK. Data tersebut berupa data kuantitatif.

Data sekunder yang digunakan adalah data yang berasal dari publikasi, literatur, maupun buku-buku teks yang mendukung kegiatan ini.
Metode Pengolahan dan Analisa Data

Metode yang digunakan untuk menilai perubahan tingkat pengetahuan perawat dalam Terapi Aktifitas Kelomopk adalah one group pretest posttest design (Sugiyono, 2013) dengan total sampel 23 perawat jiwa Rumkital dr Ramelan Surabaya.

Sebelum dilakukan pelatihan TAK Stimulasi Persepsi Halusinasi. Sebelumnya 23 perawat jiwa tersebut diberikan lembar pre test yang berisi 20 pertanyaan tentang TAK Stimulasi Persepsi Halusinasi. Kemudian disepakati pelaksanaan Pelatihan Terapi Aktifitas Kelompok Stimulasi Persepsi Halusinasi yaitu 3 hari dimulai dari tanggal 1 sampai 3 Mei 2018.

Materi tentang TAK diberikan setelah proses pre test. Materi tersebut diberikan mulai dari proses pembuatan proposal TAK dan persiapannya. Hari ke 2 pelatihan dilaksanakan roleplay kelompok dengan sesama perawat. Hari ke 3 Roleplay langsung dilaksanakan pada pasien. Selama tahap pelaksanaan tersebut dilakukan observasi kemampuan perawat melalui lembar observasi.

Tahap terakhir adalah tahap post test dimana perawat diberikan 20 pertanyaan post test. Kemudian didapatkan hasil perbedaan pengetahuan dan kemampuan perawat sebelum dan sesudah pelaksanaan pelatihan TAK yang merupakan salah satu bentuk pengabdian masyarakat yang dilakukan oleh STIKES Hang Tuah Surabaya.

\section{HASIL DAN PEMBAHASAN}

Hasil kegiatan pengabdian masyarakat ini dapat diukur dengan melakukan tes sebelum dan sesudah (pretest posttest) dengan memberikan Pelatihan TAK Stimulasi Persepsi Halusinasi pada perawat jiwa di Ruang 6 Rumkital DR Ramelan Surabaya.

\section{Pelaksanaan TAK Stimulasi Persepsi Halusinasi.}

Terapi Aktivitas Kelompok (TAK) stimulasi persepsi adalah terapi yang 
menggunakan aktivitas yang menggunakan aktivitas mempersepsikan berbagai stimulasi yang terkait dengan pengalaman dengan kehidupan untuk didiskusikan dalam kelompok. Hasil diskusi kelompok dapat berupa kesepakatan persepsi atau alternatif penyelesaian masalah.

Terapi aktivitas kelompok stimulasi persepsi halusinasi dibagi dalam 5 sesi, yaitu : Sesi I: Klien mengenal halusinasi; Sesi II: mengontrol halusinasi dengan cara menghardik; Sesi III: Mengontrol halusinasi dengan cara bercakap-cakap dengan orang lain; Sesi IV: Mengontrol halusinasi dengan cara melakukan aktivitas terjadwal; Sesi V: Mengontrol halusinasi dengan cara patuh minum obat (Keliat, 2013)

Pengabdian masyarakat kali ini sasaran yang akan diukur adalah pengetahuan perawat tentang TAK Stimulasi Persepsi Sensori Halusinasi. Diharapkan pengetahuan perawat meningkat sehingga pelaksanaan terapi kelompok pada pasien melalui TAK dilakukan secara rutin dan mampu meningkatkan kemampuan pasien serta menurunkan tanda dan gejala pasien.

\section{Perubahan Pengetahuan Perawat Tentang TAK Stimulasi Persepsi Halusinasi \\ Perubahan pengetahuan} peraway dalam pengabdian masyarakat ini dapat dilihat dari hasil sebelum dan sesudah pemberian pelatihan TAK Stimulasi Persepsi Sensori Halusinasi. Data awal sebelum diberikan pelatihan TAK Stimulasi Persepsi Sensori Halusinasi didapatkan hasil 3 perawat (13\%) memiliki kemampuan baik, 10 perawat $(43,5 \%)$ memiliki kemampuan cukup dan 10 perawat $(43,5 \%)$ memiliki kemampuan kurang. Hasil data setelah pemberian pelatihan TAK Stimulasi Persepsi Halusinasi yaitu 15 perawat $(65,2 \%)$ memiliki kemampuan baik, 5 perawat berkemampuan cukup $(21,7 \%)$ dan 3 perawat (13\%) berkemampuan kurang. Melalui data tersebut terlihat adanya peningkatan kemampuan kemampuan perawat tentang TAK
Stimulasi Persepsi Halusinasi dengan hasil uji statistik menggunakan Uji Wilcoxon dengan nilai $\mathrm{p}=0.001<\alpha$ $(\alpha=0.05)$.

Upaya keberlanjutan kegiatan pelatihan TAK sebagai bentuk pengabdian masyarakat tersebut akan diarahkan pada kegiatan pendampingan dan pembimbingan secara kontinu dengan memasukkan TAK tersebut kedalam aktifitas harian pasien di Ruang 6 Rumkital Dr. Ramelan Surabaya. Melalui kegiatan ini diharapkan pihak perawat dan Departemen Keperawatan Rumkital DR Ramelan Surabaya mampu mempertahankan aktifitas terjadwal pasien agar penurunan tanda dan gejala serta peningkatan kemampuan pasien terjadi. Selain itu pengetahuan dan kemampua perawat tentang TAK dapat senantiasa diasah agar membudaya sebagai bentuk asuhan keperawatan yang profesional.

\section{KESIMPULAN}

Berdasarkan hasil dan pembahasan kegiatan pengabdian masyarakat ini dapat disimpulkan bahwa terjadi perubahan yang signifikan dari kemampuan perawat sebelum dan sesudah pemberian Pelatihan TAK Stimulasi Persepsi Halusinasi dengan rincian sebagai berikut

1. Pengetahuan perawat tentang TAK sebelum pelaksanaan pelatihan TAK mayoritas cukup.

2. Pengetahuan perawat tentang TAK setelah pelaksanaan pelatihan TAK mayoritas baik.

3. Pengetahuan perawat tentang TAK mengalami peningkatan setelah diberikan pelatihan TAK Stimulasi Persepsi Halusinasi.

\section{DAFTAR PUSTAKA}

Ali Zaidin, (2002). Dasar-dasar Keperawatan Profesional, Jakarta:EGC

Ari Kunto Suharsini, (2010). Prosedur Penelitian Suatu Pendekatan Praktek, Jakarta:Rineka Cipta. 
Asmadi. 2008. Konsep Dasar Keperawatan, Jakarta: EGC.

DEPKES RI: Direktorat Kesehatan Jiwa (2010). Petunjuk Teknis Terapi Aktivitas Kelompok Pasien Mental di Rumah Sakit:Jakarta.

Gunawan, Ari. (2000). Sosiologi Pendidikan, Jakarta:Rineka Cipta.

Hidayat, Azis dan Musrifatul Uliyah. (2003). Riset Keperawatan Profesional, Jakarta:Widya Medika.

http://www.carigold.com/portal/forms/ar chieve/index.php/t371618.tml diakses Minggu, 10 Januari 2018 pukul 20.05 WIB).

http://eprints.uny.ac.id diakses Senin, 11 Januari 2018 pukul 07.56 WIB

Isaacs, Ann. (2005). Keperawatan Kesehatan Jiwa dan Psikiatrik, Jakarta:EGC.

Keliat, B.A. dan Pawirowiyono, Akemat, 2013. Keperawatan Jiwa Terapi Aktivitas Kelompok, Jakarta: EGC.

Kusnanto. (2004). Pengantar Profesi dan Praktek Keparawatan Profesional, jakarta:EGC.

Nasir, Abdul. 2011. Dasar-Dasar Keperawatan Jiwa: Pengantar dan Teori, Jakarta: Salemba Medika.

Notoatmodjo, Soekidjo. (2007). Promosi Kesehatan dan Ilmu Perilaku, Jakarta:Rineka Cipta.

Notoatmodjo, Soekidjo. (2002). Metodologi Penelitian Kesehatan, Jakarta:Rineka Cipta.

Nursalam dan Siti Pariani. (2001). Pendekatan praktis Metodologi Riset Keperawatan, CV Info Media.

Potter, Perry. 2007. Fundamental Keperawatan, Jakarta: Salemba Medika.
Setiadi.(2007).Konsep dan Penulisan Riset Keperawatan, Jogyakarta:Graha Ilmu.

Severin, J Werner. (2005). Teori Komunikasi Sejarah Metode Dan Terapan Dala Media Massa. Jakarta: Prenada Media.

Stuart GW dan Laraia MT. (1998). Principles dan practice Of Psychiatric Nursing 6 th ed, st Louis : Mosby.

Stuart dan Sundeen, (1998). Buku Saku Keperawatan Jiwa, Jakarta:EGC.

Sugiyono, (2003) Statistika Untuk Penelitian, Bandung:CV Alpabeta.

Susanna, Sarka Ade Et all. (2007). Terapi Modalitas dalam Keperawatan Jiwa, Jogyakarta:Mitra Cendika.

Susana, S.A dan Hendarsih, Sri. 2011. Terapi Modalitas Keperawatan Kesehatan Jiwa, Jakarta: EGC.

Setyoadi dan Kushariyadi. 2011. Terapi Modalitas Keperawatan pada Klien Psikogeratrik, Jakarta: Salemba Medika.

Videbeck, Sheila. 2008. Buku Ajar Keperawatan Jiwa, Jakarta: EGC.

\begin{tabular}{lcr} 
& (2003). & Makalah \\
\hline Pelatihan & Nasional & Terapi \\
Modalitas & Keperawatan & Jiwa, \\
RSJP Lawang. &
\end{tabular}

